\title{
Raleio químico de frutos de ameixeira com ethephon
}

\author{
Chemical thinning of plum fruits with ethephon
}

\section{Alexandre Pozzobom Pavanello ${ }^{\mathrm{I}^{*}}$ Ricardo Antônio Ayub ${ }^{\mathrm{I}}$}

\section{RESUMO}

$O$ raleio promove equilíbrio entre o crescimento vegetativo e produtivo, aumento no tamanho dos frutos e evita alternância da produção. O objetivo deste trabalho foi avaliar $o$ efeito de diferentes concentrações de ethephon no raleio químico de frutos das ameixeiras cultivares 'Irati'e 'Reubennel', na região de Arapoti-PR. Os tratamentos foram cinco concentrações de ethephon (0, 60, 80, 100, $\left.120 \mu \mathrm{L} \mathrm{L}^{-1}\right)$ para cultivar 'Irati' e quatro concentrações (0, 60, 80, $\left.120 \mu L L^{-1}\right)$ para a cultivar 'Reubennel', aplicadas quando os frutos apresentavam $5 \mathrm{~mm}$ de diâmetro. Foram avaliados: produção por planta, massa dos frutos, calibre, teor de sólidos solúveis, firmeza, acidez titulável, $\mathrm{pH}$ e coloração dos frutos. Na concentração de $120 \mu \mathrm{L} \mathrm{L} \mathrm{L}^{-1}$ de ethephon a cultivar 'Irati' produziu $20 \mathrm{~kg}$ planta $^{-1}$ e a cultivar 'Reubennel' $56 \mathrm{~kg}$ planta $^{-1}$, apresentando quantidade satisfatória de frutos com calibre III e IV. Não houve diferença significativa entre os tratamentos para as variáveis firmeza, sólidos solúveis, $p H$, acidez e coloração, avaliadas na pós-colheita para as duas cultivares de ameixeira.

Palavras-chave: Prunus salicina, ácido 2-cloroetilfosfônico, frutificação.

\section{ABSTRACT}

Thinning of plum trees promotes balance between vegetative growth and production, increases the fruit size and avoids alternation of production. The objective of this study was to evaluate the effect of different ethephon concentrations as chemical thinning of plum cv. 'Irati' and cv. 'Reubennel', in Arapoti-PR. Five treatments with ethephon were evaluated at dosages $(0,60,80$, 100, $\left.120 \mu \mathrm{L} \mathrm{L} \mathrm{L}^{-1}\right)$ in $\mathrm{cv}$. 'Irati' and four treatments at dosages; 0; 60; 80; $120 \mu L L^{-1}$ in $c v$. 'Reubennel', all applied when fruits diameter was $5 \mathrm{~mm}$ followed by measurements plant yield, weight, size, soluble solids, firmness, titratable acidity, $\mathrm{pH}$ and color of fruits. At a concentration of $120 \mu \mathrm{L} \mathrm{L}{ }^{-1}$ ethephon, $\mathrm{cv}$. 'Irati' produced $20 \mathrm{~kg}$ plant $^{-1}$ and the $\mathrm{cv}$. 'Reubennel' $56 \mathrm{~kg}^{\text {plant }}{ }^{-1}$ presenting satisfactory quantity of fruit size III and IV. There was no significant difference between treatments for variable firmness, soluble solids, titratable acidity, $\mathrm{pH}$ and color of fruits evaluated in the post-harvest for the two plum cultivars.

Key words: Prunus salicina, 2-chloroethylphosphonic acid, fruit set.

A ameixeira (Prunus salicina Lindl) frequentemente apresenta alta intensidade de florescimento e este excesso permanecendo na planta até a colheita resultará em frutos pequenos e de baixa qualidade comercial, podendo quebrar os ramos e reduzir o florescimento do ano seguinte.

Para alcançar um bom rendimento anual e frutos de alta qualidade recomenda-se ralear as flores ou frutos com um produto químico, e após a queda natural dos frutos, fazer os ajustes de carga com o raleio manual. Essa técnica pode reduzir os custos de mão-de-obra e melhorar o valor comercial dos frutos remanescentes, os quais terão maior calibre (MELAND \& BIRKEN, 2010; PAVANELLO \& AYUB, 2012).

A ação fisiológica da maioria dos raleantes químicos é desencadear um desequilíbrio entre os fluxos no transporte de auxina, ocasionando abscisão. O ethephon (ácido 2-cloroetilfosfônico) é um inibidor do transporte de auxina que, pela liberação de etileno, estimula sua síntese ocasionando a queda dos frutos (BANGERTH, 2000).

O raleio químico de floração mostrase mais efetivo, entretanto, frutíferas de caroço

'Universidade Estadual de Ponta Grossa (UEPG), Departamento de Fitotecnia e Fitossanidade, Av. Carlos Cavalcanti, CP 4748, 84030-900, Ponta Grossa, PR, Brasil. E-mail: alexandrepavanello@ hotmail.com. *Autor para correspondência. 
cultivadas em regiões frias, o risco de perda de safra, em razão da ocorrência de geadas após o raleio, aumenta consideravelmente. Assim, o raleio após a florada, na fase de fixação dos frutos pode ser mais vantajoso, pois permite também uma avaliação mais exata da frutificação (WEBER, 2013).

Uma única aplicação de $250 \mu \mathrm{L} \mathrm{L}^{-1}$ de ethephon na fase de floração ou $75 \mu \mathrm{L} \mathrm{L}^{-1}$ de ethephon $+10 \mathrm{mg} \mathrm{L}^{-1}$ de ANA um mês após a plena florada, reduziu a frutificação, aumentou a qualidade dos frutos e o retorno da floração na cultivar 'Victoria' (MELAND, 2007) e para cultivar 'Jubileum', a aplicação de $375 \mu \mathrm{L} \mathrm{L}^{-1}$ de ethephon na fase de floração ou $250 \mu \mathrm{L} \mathrm{L}^{-1}$ de ethephon com frutos de 10 $\mathrm{mm}$ de diâmetro, reduziram a frutificação para $10 \mathrm{a}$ 15 frutos por 100 flores, a qual proporciona frutos com maior tamanho, que atendem às exigências dos consumidores (MELAND \& BIRKEN, 2010).

Muitos fatores devem ser levados em conta quando ethephon for usado como raleante químico, dentre eles, a cultivar, volume de calda, época de aplicação, concentração e temperatura (MARINI, 2004).

Nesse contexto, o objetivo deste trabalho foi avaliar o efeito de diferentes concentrações de ethephon (ácido 2-cloroetilfosfônico) no raleio químico das ameixeiras cultivares 'Irati' e 'Reubennel', na região de Arapoti-PR, centro leste do Paraná.

O experimento foi desenvolvido de julho a dezembro de 2011 em pomar comercial de ameixeira cultivar 'Irati' com 5 anos de idade e cultivar 'Reubennel' com 3 anos de idade, ambas sobre o portaenxerto A-9 em espaçamento 5,0 x 2,5 m, conduzidas no sistema de vaso, no município de Arapoti-PR. As coordenadas geográficas de referência são $24^{\circ} 07^{\prime} 20^{\prime}$ " sul e 49\%46' $52^{\prime \prime}$ " oeste e a altitude do local é $850 \mathrm{~m}$.

Para a cultivar 'Irati', os tratamentos foram cinco concentrações de ethephon $(0,60,80,100,120$ $\left.\mu \mathrm{L} \mathrm{L}^{-1}\right)$ e para cultivar 'Reubennel' foram quatro concentrações de ethephon $\left(0,60,80,120 \mu \mathrm{L} \mathrm{L}^{-1}\right)$, aplicadas com $700 \mathrm{~L} \mathrm{ha}^{-1}$ de volume de calda, 30 dias após a plena florada, quando os frutos apresentavam 5 mm de diâmetro (estádio chumbinho) com queda dos restos florais. O produto comercial utilizado foi Ethrel $240^{\circledR}$ (Ethephon $240 \mathrm{gL}^{-1}(24 \% \mathrm{~m} / \mathrm{v})$ ) e o pulverizador utilizado para aplicação foi atomizador $1500 \mathrm{~L}$.

Foram avaliadas a produção de frutos por planta $(\mathrm{kg})$, a massa média (g) e o calibre dos frutos. Este foi determinado com máquina classificadora $\mathrm{e}$ é relacionado ao diâmetro: Calibre II (4,0 a 4,4 cm); Calibre III (4,5 a 4,9 cm); e Calibre IV (5,0 a 5,5 cm); sendo expresso em percentual de cada calibre em relação ao número total de frutos. O teor de sólidos solúveis ( ${ }^{\circ}$ Brix) foi determinado com refratômetro digital. A firmeza da polpa dos frutos foi determinada com auxílio de penetrômetro, com ponteira de $8 \mathrm{~mm}$ de diâmetro e os valores expressos em (N). A acidez titulável da polpa foi determinada da solução de 10 $\mathrm{mL}$ de suco diluído em $100 \mathrm{~mL}$ de água destilada por titulação com hidróxido de sódio ( $\mathrm{NaOH} 0,1$ Molar), até $\mathrm{pH} 8,1$. A acidez foi expressa em porcentagem de ácido málico. $\mathrm{O} \mathrm{pH}$ foi medido com pHmetro digital. A coloração superficial foi determinada com colorímetro (Minolta CR400 ${ }^{\circledR}$, Osaka, Japão) e a partir de dados dessas determinações, calculou-se o ângulo hue, em que ângulo $0^{\circ}$ representa vermelho puro, $90^{\circ}$ representa o amarelo puro, $180^{\circ}$ o verde puro e o $270^{\circ}$ o azul (LANCASTER et al. 1997).

$\mathrm{O}$ delineamento experimental foi $\mathrm{em}$ blocos ao acaso, com cinco tratamentos e quatro repetições no experimento com a cultivar 'Irati' e quatro tratamentos com cinco repetições no experimento com a cultivar 'Reubennel'. Foram utilizadas cinco plantas por parcela experimental para aplicação dos tratamentos e avaliou-se a planta do meio. Os resultados foram submetidos à análise de variância e, quando houve diferença significativa entre os tratamentos, procedeu-se à análise de regressão polinomial pelo método geral, utilizando o software SISVAR 5.3 (FERREIRA, 2010).

Para cultivar 'Irati', a maior produção de frutos foi $23 \mathrm{~kg} /$ planta $^{-1}$ com a concentração estimada de $70 \mu \mathrm{L} \mathrm{L}^{-1}$ de ethephon, em que a testemunha apresentou $17 \mathrm{~kg} /$ planta $^{-1}$. Para cultivar 'Reubennel' a maior produção foi $83 \mathrm{~kg} /$ planta $^{-1}$ com a concentração estimada de $20 \mu \mathrm{LL}^{-1}$ de ethephon, em que a testemunha apresentou $75 \mathrm{~kg}_{\text {planta }}{ }^{-1}$ (Figura $1 \mathrm{~A}$ ). Entretanto, nestas concentrações de ethephon apresentadas, a quantidade de frutos de calibre III e IV não são interessantes para comercialização, sendo a concentração de $120 \mu \mathrm{L} \mathrm{L}^{-1}$ de ethephon a qual apresenta a maior porcentagem de frutos calibre III e IV (Figura C e D), diminuindo um pouco a produção (Cultivar 'Irati' $20 \mathrm{~kg}$ planta $^{-1}$ e cultivar 'Reubennel' $56 \mathrm{~kg}$ planta $^{-1}$ ) (Figura $1 \mathrm{~A}$ ) contudo, reduz o número de frutos por planta, diminui as horas homem de raleio manual, menores custos com colheita, menos embalagens, facilidade na comercialização proporcionando uma maior receita líquida. Nas últimas safras, os produtores vêm encontrando dificuldade em vender frutos de calibre I e II, os quais apresentam preços entre R $\$ 0,50$ a 1,00 $\mathrm{kg}$, enquanto, em frutos de calibre III e IV, os valores de venda chegam a R\$3,00 kg fruta (INFORMAÇÃO PESSOAL).

Segundo MELAND \& BIRKEN (2010), a cultivar 'Jubileum' apresentou 13,0 kg planta-1 $^{-1}$ 
na concentração $125 \mu \mathrm{L} \mathrm{L}^{-1}$ de ethephon, em que a testemunha produziu $21,5 \mathrm{~kg}$ planta $^{-1}$. Para cultivar 'Victoria' com aplicação de ethephon $75 \mu \mathrm{L} \mathrm{L}^{-1}$ de ethephon $+10 \mathrm{mg} \mathrm{L}^{-1}$ de ANA, apresentou produção de $12,6 \mathrm{~kg}_{\text {planta }}{ }^{-1}$, em que a testemunha apresentou 22,7 kg planta ${ }^{-1}$ (MELAND, 2007). De acordo com WEBER (2013), há grande diferença na produtividade entre as cultivares e isso se deve a fatores genéticos, climáticos e de manejo da cultura (porta-enxerto, espaçamento, idade das plantas, sistema de condução, poda, produção anterior e adubação).

Para cultivar 'Irati', o aumento da concentração de Ethephon diminuiu linearmento o percentual de frutos calibre II, enquanto para cultivar 'Reubennel' a redução de frutos com este calibre ocorreu a partir da concentração $56 \mu \mathrm{L} \mathrm{L}^{-1}$ de ethephon (Figura $1 \mathrm{~B})$.

$\mathrm{O}$ aumento na concentração de ethephon aumentou linearmente o percentual de frutos de calibre III de ambas as cultivares de ameixeira (Figura $1 \mathrm{C}$ ). Este resultado é coerente, pois com a intensificação do raleio, há redução do número de frutos por planta, com consequente aumento no calibre dos frutos remanescentes.

O aumento na concentração de ethephon aumentou linearmente o número de frutos de calibre IV para cultivar 'Irati'. Na cultivar 'Reubennel', somente os tratamentos com as concentrações 80 e 120 $\mu \mathrm{L} \mathrm{L}^{-1}$ apresentaram frutos calibre IV, provavelmente devido à grande quantidade de frutos por planta (Figura 1 D). PAVANELLO \& AYUB (2012), com 93 $\mu \mathrm{L} \mathrm{L}^{-1}$ de Ethephon, verificaram o maior número de frutos calibre IV para cultivar 'Irati'.

O aumento da concentração de ethephon aumentou linearmente a massa média dos frutos de ambas as cultivares de ameixeira (Figura $1 \mathrm{E}$ ). Houve um acréscimo de $16 \%$ e $40 \%$ na massa dos frutos entre a testemunha e a maior concentração de ethephon, para as cultivares 'Irati' e 'Reubennel', respectivamente. Com a intensificação do raleio e redução no número de frutos, há uma menor competição, ocasionando um aumento na massa média dos frutos. Na cultivar 'Reubennel', por ser tardia, os frutos permanecem por um maior período



Ciência Rural, v.44, n.10, out, 2014. 
na planta e tendem a desenvolver mais, quando comparados com os frutos da cultivar 'Irati', que é mais precoce. Segundo MELAND \& BIRKEN (2010) em experimento desenvolvido no ano de 2007 , estudos mostraram que quanto maior a concentração de ethephon maior a massa média dos frutos.

Não houve diferença significativa entre os tratamentos para as variáveis firmeza, sólidos solúveis, $\mathrm{pH}$, acidez e coloração, avaliadas na póscolheita para as duas cultivares de ameixeira. Para cultivar 'Irati' o valor médio de firmeza foi $18,5 \mathrm{~N}$. Para cultivar 'Reubennel' o valor médio de firmeza foi $30 \mathrm{~N}$, o que confirma o resultado de BRACKMANN et al., (2005). Para cultivar 'Jubileum' a aplicação de diferentes concentrações de ethephon não influenciou na firmeza dos frutos segundo MELAND \& BIRKEN (2010).

A cultivar 'Irati' apresentou em média 12,4 ${ }^{\circ}$ Brix, 0,76\% de ácido málico e $\mathrm{pH}$ 2,81 e a cultivar 'Reubennel' apresentou em média 16,5 ${ }^{\circ}$ Brix, 0,79\% de ácido málico e $\mathrm{pH} 2,75$. Isto demonstra a qualidade superior da cultivar 'Reubennel' em relação à cultivar 'Irati', que é mais ácida. A coloração não foi beneficiada pela utilização do ethephon para cultivar 'Irati', cujo ângulo hue médio foi de 23,8. Para cultivar 'Reubennel' o ângulo hue médio foi de 35,5.

A concentração de $120 \mu \mathrm{L} \mathrm{L}^{-1}$ de ethephon proporciona quantidade satisfatória de frutos calibre III e IV, para ambas cultivares, com produção de 20 $\mathrm{kg} /$ planta $^{-1}$ para cultivar Irati e $56 \mathrm{~kg} /$ planta $^{-1}$ para cultivar 'Reubennel'. Nenhuma das concentrações de ethephon testadas afeta a qualidade física e química dos frutos em relação ao teor de sólidos solúveis, firmeza, $\mathrm{pH}$, acidez e coloração para ambas cultivares.

\section{REFERÊNCIAS}

BANGERTH, F. Abscission and thinning of young fruit and their regulation by plant hormones and bioregulators. Plant Growth Regulation, v.31, p.43-59, 2000. Disponível em: <http://link. springer.com/article/10.1023\%2FA\%3A1006398513703\#pa ge-1>. doi: 10.1023/A: 1006398513703 .

BRACKMANN, A.et al. Armazenamento de ameixas cultivares 'Reubennel' e 'Pluma 7' sob diferentes temperaturas, em atmosfera controlada e refrigerada. Revista Brasileira de Agrociência, v.11, n.1, p.85-89, 2005.

FERREIRA, D.F. SISVAR - Sistema de análise de variância. v.5.3. Lavras: UFLA, p. 95, 2010.

LANCASTER, J.E.et al. Influence of pigment composition on skin color in a wide range of fruit and vegetables. Journal of American Society of Horticultural Science, v.122, p.594-598, 1997.

MARINI, R.P. Combinations of ethephon and Accel for thinning 'Delicious' apple tree. Journal of the American Society for Horticultural Science, v.192, p.175-181, 2004.

MELAND, M. Efficacy of chemical bloom thinning agents of European plums. Acta Agriculturae, Scandinavica, Sec. B, v.57, p.235-242, 2007. Disponível em: <http://www.tandfonline.com/ doi/full/10.1080/09064710600914236\#.U1fftfldUZ4>. Acesso em: 22 abril. 2014. doi: 10.1080/09064710600914236.

MELAND, M.; BIRKEN, E. Ethephon as a Blossom and Fruitlet Thinner Affects Crop Load, Fruit Weight and Fruit Quality of the European Plum Cultivar 'Jubileum'. Acta Horticulturae, v.884, p.315-321, 2010.

PAVANELLO, A. P.; AYUB, R. A. Aplicação de Ethephon no Raleio Químico de Ameixeira e seu Efeito Sobre a Produtividade. Revista Brasileira de Fruticultura, v.34, n.1, p.309-316, 2012.

WEBER, H, J. Chemical and Mechanical Thinning of Plums. Acta Horticulturae. v. 998, p.51-59, 2013. 